\title{
A NOVEL P-Q CONTROL ALGORITHM FOR COMBINED ACTIVE FRONT END CONVERTER AND SHUNT ACTIVE FILTER
}

\author{
SH Suresh Kumar Budi ${ }^{1}$, Biswa Bhusan Dash ${ }^{2}$ \\ ${ }^{1} P G$ Student, ${ }^{2}$ Associate professor, GITS, Bobbili, Vizinagaram Dist \\ bsrihari99@gmail.com,viswandash@gmail.com
}

\begin{abstract}
This paper presents a combined active front-end converter and shunt active filter (AFE+SAF) controlled by $p$ - $q$ theory control algorithm. The Combined AFE+SAF is able to compensate reactive power, harmonic power and unbalanced power produced by unbalanced linear, non linear and at the same time three phase AC to DC power conversion AFE+SAF will not pollute the source currents. The $p-q$ theory control algorithm is able to meat the target of load compensation and three phase AC to DC (for drives) conversion. the AFE+SAF verified by simulation for different cases as unbalanced linear load, non linear load, unbalanced linear and non linear load, unbalanced linear non linear and drive load. The whole simulation has been carried out on the mat lab/ simulink software.
\end{abstract}

Keywords:- active front-end converter, shunt active power filter, p-q theory, power quality, harmonics, reactive power.

\section{INTRODUCTION}

In the last half a century years an increased number of power electronic equipments connected to the grid cause the decrease of power quality of the grid. In Last two decade years active front end converters (AFE) are substitute for the diode rectifiers or thyristor rectifiers in variable speed drives. Even though the thyristor based rectifiers and diode rectifiers are at low cost and high reliable, AFEs [1][3-10]are used for drives because bidirectional power flow capability, selectable power factor capability, sinusoidal source currents and line supply voltage capability etc., shunt active filters and series active filters are used for the compensate harmonics and reactive power at the grid. The drawback of the active filters is the regenerative capability for drives. Load compensation can efficiently achieved by the active filters and AFE [12-16]are able to maintain the source currents as sinusoidal, regenerative capability hence the combination of these advantages can make one converter as combined active front end converter and shunt active filter (AFE+SAF).

The proposed control algorithm is suitable acts as AFE+SAF and it solves the problem of regenerative capability, load compensation and power factor control etc. IGBT three leg bridge with midpoint capacitor converter is used as the [16] AFE+SAF power electronic converter. The very famous pq [2] control algorithm is to calculate the reference currents for the converter. The objective of the pq theory is to convert the three phase system into the single phase system so that computation of the real power and imaginary powers easy and then compensate as requirement of the system. In this paper pq theory compensate reference currents are given separately for active front converter, shunt active filter and AFE+SAF.
To evaluate the performance of the AFE+SAF, considered different cases such as (i) DC Side Equivalent Drive load, (ii) Unbalanced Linear Load, (iii) Non Linear Load, (iv) Unbalanced Linear and Non Linear Load, (v) Unbalanced Linear, Non Linear and DC Side Equivalent Drive load. For all considered cases the proposed converter is able to meet target of compensation. A performance index is used to measure the distortion in source line currents is known as \% THD and its values are observed that in the premises of IEEE Std. 519 [17] standard.

The organization of the paper is as follows, in section I, it gives introduction about the AFE and shunt active filter. The section II, pq theory control algorithm derived for the active front converter, SAF and AFE+SAF. in section III, the schematic diagram of the AFE+SAF converter is explained. In the section IV, simulation results and discussion of the considered system for different cases have been included. the final conclusion of the carried work about the AFE+SAF control by pq theory has been concluded in the section $\mathrm{V}$.

\section{CONTROL ALGORITHM}

Instantaneous p-q Theory to deal with instantaneous voltages and currents in three phase circuits mathematically, it is adequate to express their quantities as the instantaneous space vectors.[2][16]

Transform the voltages and currents from $a-b-c_{\text {to }} \alpha-\beta-o$ frame, 


$$
\left[\begin{array}{l}
x_{\alpha} \\
x_{\beta} \\
x_{0}
\end{array}\right]=\sqrt{\frac{2}{3}}\left[\begin{array}{ccc}
1 & -\frac{1}{2} & -\frac{1}{2} \\
0 & \frac{\sqrt{3}}{2} & -\frac{\sqrt{3}}{2} \\
\frac{1}{\sqrt{2}} & \frac{1}{\sqrt{2}} & \frac{1}{\sqrt{2}}
\end{array}\right]\left[\begin{array}{l}
x_{a} \\
x_{b} \\
x_{c}
\end{array}\right]
$$

Since the system is to be consisting only positive sequence components such that system can balanced and harmonic free. The above equation derived from the instantaneous positive sequence symmetrical components i.e.,

$$
v_{\alpha \beta}=\sqrt{\frac{2}{3}}\left(v_{a}+a v_{b}+a^{2} v_{c}\right)
$$

Where

$$
a=e^{j \frac{2 \pi}{3}}=\cos \left(\frac{2 \pi}{3}\right)+j \sin \left(\frac{2 \pi}{3}\right)
$$

The above equation separated into real and imaginary components,

Real term

$$
v_{\alpha}=\sqrt{\frac{2}{3}}\left(v_{a}-\frac{1}{2} v_{b}-\frac{1}{2} v_{c}\right)
$$

Imaginary term

$$
v_{\beta}=\sqrt{\frac{2}{3}}\left(\frac{\sqrt{3}}{2} v_{b}-\frac{\sqrt{3}}{2} v_{c}\right)
$$

The same is true for the current expressions. Instantaneous space phasor is rotating with angular speed of

$$
\frac{d \theta}{d t}=\operatorname{Tan}^{-1}\left(\frac{v_{\beta}}{v_{\alpha}}\right)
$$

From the source system has to supply only active power, which is equally supplied through the individual phases.

The power from the supply derived by the p-q theory

$$
s=v_{\alpha \beta}{ }^{*} i_{\alpha \beta}{ }^{*}=\left(v_{\alpha}+j v_{\beta}\right) *\left(i_{\alpha}-j i_{\beta}\right)=v_{\alpha} i_{\alpha}+v_{\beta} i_{\beta}-j\left(v_{\alpha} i_{\beta}-v_{\beta} i_{\alpha}\right)_{(7)}
$$

The load is requires only active power, hence

$$
v_{\alpha} i_{\alpha}+v_{\beta} i_{\beta}=P_{d c}=p_{\alpha \beta}
$$

And there is no need of reactive power in load side hence

$$
v_{\alpha} i_{\beta}-v_{\beta} i_{\alpha}=0=q_{\alpha \beta}
$$

When the unbalance system involves zero sequence components come into picture, The Load doesn't need any unbalanced power

$$
P_{o}=v_{o} * i_{o}=0
$$

The above equations can written as

$$
\left[\begin{array}{l}
p_{o} \\
p_{\alpha \beta} \\
q_{\alpha \beta}
\end{array}\right]=\left[\begin{array}{ccc}
v_{0} & 0 & 0 \\
0 & v_{\alpha} & v_{\beta} \\
0 & -v_{\beta} & v_{\alpha}
\end{array}\right]\left[\begin{array}{l}
i_{0} \\
i_{\alpha} \\
i_{\beta}
\end{array}\right]
$$

The current equations can written as

$$
\left[\begin{array}{c}
i_{0} \\
i_{\alpha} \\
i_{\beta}
\end{array}\right]=\frac{1}{v_{0} v_{\alpha \beta}^{2}}\left[\begin{array}{ccc}
v_{\alpha \beta}^{2} & 0 & 0 \\
0 & v_{0} v_{\alpha} & -v_{0} v_{\beta} \\
0 & v_{0} v_{\beta} & v_{0} v_{\alpha}
\end{array}\right]\left[\begin{array}{l}
p_{o} \\
p_{\alpha \beta} \\
q_{\alpha \beta}
\end{array}\right]
$$

The AFE Converter capacitor is connected to the Dc side load i.e. Pdc. For the Capacitor DC Voltage regulation, PI control is used i.e., The error of the voltage is pass through the PI controller, gives $\mathrm{Pc}$ which is proportional to the amount of real power which needs to maintain the DC capacitor Voltage. Hence

$$
p_{\alpha \beta}=P_{d c}+P_{c}
$$

Active Front End converter with shunt active filter compensated current equations can written as

$$
\left[\begin{array}{c}
i_{f 0} \\
i_{f \alpha} \\
i_{f \beta}
\end{array}\right]=\frac{1}{v_{0}\left(v_{\alpha}{ }^{2}+v_{\beta}^{2}\right)}\left[\begin{array}{ccc}
v_{\alpha}{ }^{2}+v_{\beta}{ }^{2} & 0 & 0 \\
0 & v_{0} v_{\alpha} & -v_{0} v_{\beta} \\
0 & v_{0} v_{\beta} & v_{0} v_{\alpha}
\end{array}\right]\left[\begin{array}{c}
p_{o} \\
P_{l \alpha \beta}-P_{l \alpha \beta a v g}-P_{d c}-P_{c} \\
q_{l}
\end{array}\right]
$$

When there is no external load to PCC except Active Front End converter $i_{l a}=i_{l b}=i_{l c}=0$ the compensated currents are

$$
\left[\begin{array}{c}
i_{f 0} \\
i_{f \alpha} \\
i_{f \beta}
\end{array}\right]=\frac{1}{v_{0}\left(v_{\alpha}{ }^{2}+v_{\beta}^{2}\right)}\left[\begin{array}{ccc}
v_{\alpha}{ }^{2}+v_{\beta}^{2} & 0 & 0 \\
0 & v_{0} v_{\alpha} & -v_{0} v_{\beta} \\
0 & v_{0} v_{\beta} & v_{0} v_{\alpha}
\end{array}\right]\left[\begin{array}{c}
p_{o} \\
-P_{d c}-P_{c} \\
q_{l}
\end{array}\right]
$$

When Active Front End converter acts as shunt active filter $I_{d c}=0$ the compensated currents are 


$$
\left[\begin{array}{c}
i_{f 0} \\
i_{f \alpha} \\
i_{f \beta}
\end{array}\right]=\frac{1}{v_{0}\left(v_{\alpha}^{2}+v_{\beta}^{2}\right)}\left[\begin{array}{ccc}
v_{\alpha}^{2}+v_{\beta}^{2} & 0 & 0 \\
0 & v_{0} v_{\alpha} & -v_{0} v_{\beta} \\
0 & v_{0} v_{\beta} & v_{0} v_{\alpha}
\end{array}\right]\left[\begin{array}{c}
p_{o} \\
P_{l \alpha \beta}-P_{l \alpha \beta a v g}-P_{c} \\
q_{l}
\end{array}\right]
$$

\section{SYSTEM CONSIDERED}

The electrical system is considered in this paper for evaluating the performance AFE+SAF simulation model in matlab/Simulink is as shown in fig.1. three phase four line electrical distribution network is used to serve the loads such as domestic, industrial and signal towers etc. these loads and the compensating devices are generally connected at point of common coupling (PCC) in the system which as shown in fig.1.

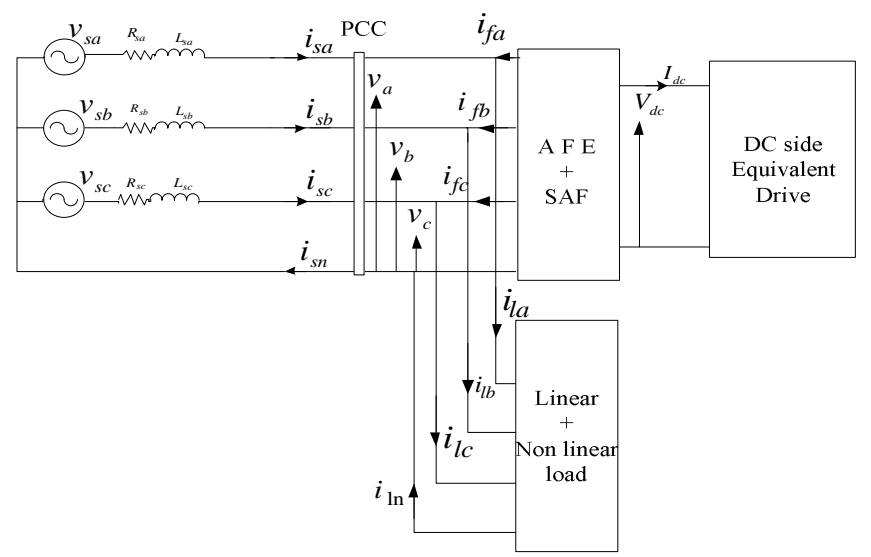

The AFE+SAF schematic circuit shown in fig.2. consists of the power electronic switches (IGBT with anti-parallel diode), filter inductance $\mathrm{Lf}$, resistance $\mathrm{Rf}$ and mid point connected capacitors which maintains the DC reference voltage. The power electronic switches can controlled by the pq theory based algorithm generated gate signals for the AFE+SAF which is shown in fig.3.

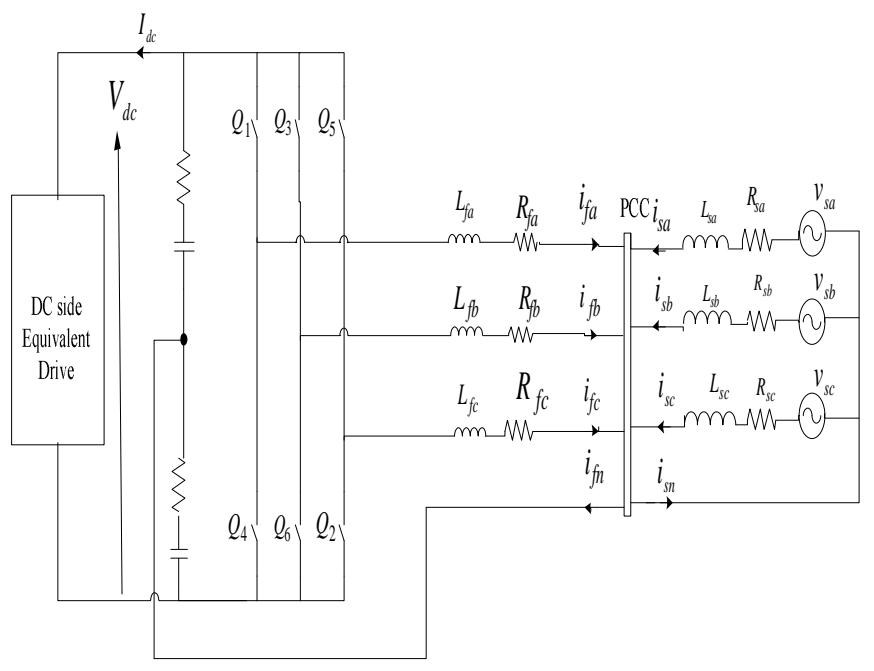

Fig.2. AFE+SAF schematic circuit

Fig.1. Electrical system model schematic diagram

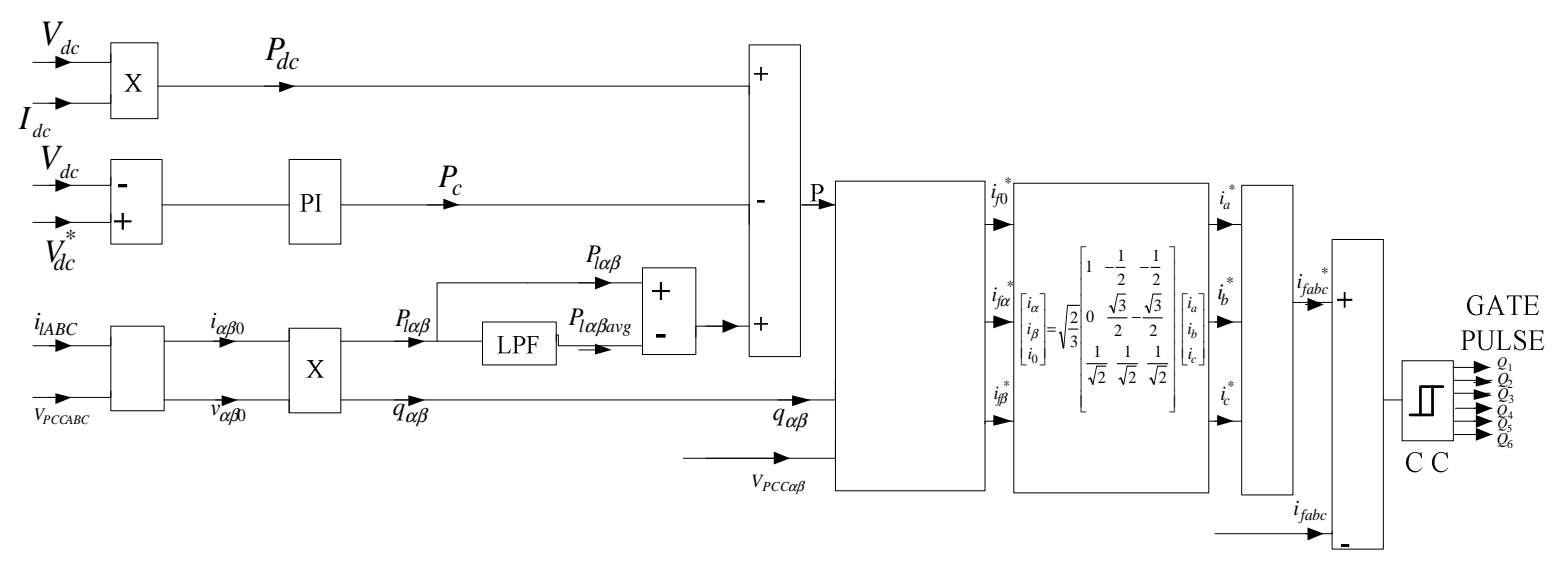

Fig.3. PQ theory based algorithm generated gate signals for the AFE+SAF

\section{SIMULATION RESUTS AND DISCUSSION}

Evaluation of the control algorithm for AFE+SAF is done by considering four different situations in the system given by Case I: DC Side Equivalent Drive load
Case II: Unbalanced Linear Load

Case III: Non Linear Load

Case IV: Unbalanced Linear and Non Linear Load

Case V: Unbalanced Linear, Non Linear and DC Side Equivalent Drive load 
An active power filter with front end converter has been simulated in MATLAB to verify the proposed control scheme with the parameters as shown in Table I

Table 1

\begin{tabular}{|l|l|}
\hline Parameters & Numerical Values \\
\hline Three phase supply & $325 \mathrm{Vph}($ peak $), 50 \mathrm{~Hz}$ \\
\hline $\begin{array}{l}\text { Feeder impedance } \\
L_{s k}, R_{s k}, \quad \text { where } \\
k=a, b, c\end{array}$ & $0.06 \mathrm{mH}, 0.1 \Omega$ \\
\hline $\begin{array}{l}\text { Shunt impedance } \\
\text { Lshk, Rshk }\end{array}$ & $2 \mathrm{mH}, 0.05 \Omega$ \\
\hline DC link capacitance & $220 \mu \mathrm{f}$ \\
\hline Udc reference & $700 \mathrm{~V}$ \\
\hline Hysteresis band h & $.2 \mathrm{~A}$ \\
\hline
\end{tabular}

The deigned converter with above parameters in table I is tested under different load conditions as follows.

\section{Case I: DC Side Equivalent Drive Load}

In this case $\mathrm{AFE}+\mathrm{SAF}$ is provided to the only $\mathrm{DC}$ side equivalent drive such as motoring and regenerative modes, i.e. converter works as active front end converter. The performance of AFE+SAF is to maintaining the DC link voltage at $700 \mathrm{~V}$. The loading values for various time periods as shown in Table2. The simulated waveforms for this operating condition are as shown in Fig 4. The fig.4. is give information about the relation between the source currents and the PCC voltages are in phase for the motoring mode and opposite phase for regenerative mode and the source currents are fundamental positive sequence components only.

Table-2

\begin{tabular}{|l|l|}
\hline Time in Seconds & $\begin{array}{l}\text { Types of load connected to DC } \\
\text { side }\end{array}$ \\
\hline$t=0.0$ to 0.01 & No Load \\
$t=0.01$ to 0.08 & $\begin{array}{l}\text { DC side equivalent drive load } \\
\text { of current }-10 \text { A (regenerative } \\
\text { mode) }\end{array}$ \\
\hline$t>0.08$ & $\begin{array}{l}\text { DC side equivalent drive load } \\
18 \text { A (Motoring mode) }\end{array}$ \\
\hline
\end{tabular}
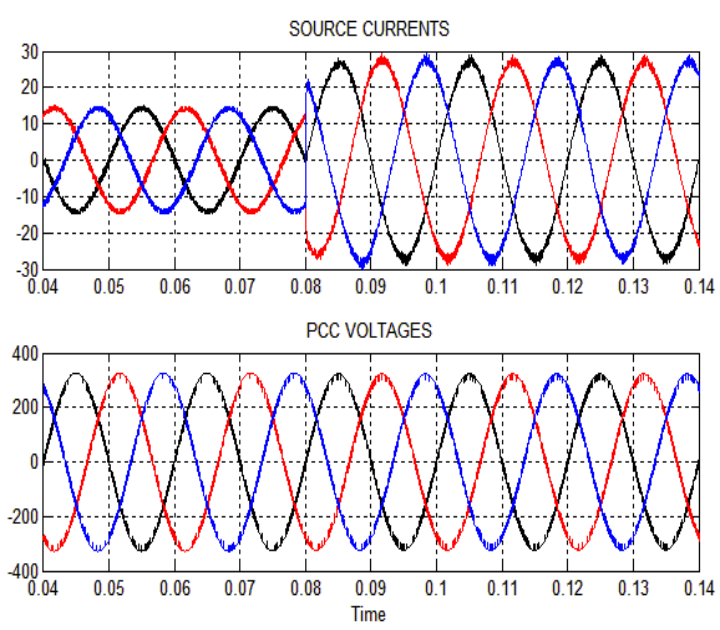

Fig 4. Simulated results for the operation of active front-end converter with DC Side Equivalent Drive load (a)Source currents (b) PCC voltages

In general in three phase to DC conversion process harmonics have introduced in the three phase circuit, but Active Front End converter can handle the DC Side Equivalent Drive load without polluting three phase source currents. The voltage across each capacitor is forced to be equal to $350 \mathrm{~V}$ to maintain a DC voltage of $700 \mathrm{~V}$. At the beginning of operation, at $t=0$ there is no load hence the source current is zero, at $\mathrm{t}=0.01 \mathrm{~s}$ the load is applied to the DC side as -10 A of equivalent drive load which can treated as regenerative mode and from $\mathrm{t}=0.08 \mathrm{~s}$ onwards load considered for motoring mode as 18 A load connected to the DC voltage. Even though the load changes abruptly the source currents are in sinusoidal with change of magnitude. During first interval no load is applied, second interval regenerative load $-10 \mathrm{~A}$ is applied and draws the source currents of peak value $I_{a \max }=14.19 \mathrm{~A}$ and THD in an around $5.28 \%$, third interval load is an motoring mode of $18 \mathrm{~A}$, draws power from the source current magnitude of $I_{a \max }=26.83 \mathrm{~A}$ and at thd of $3.46 \%$ nearly. Source current magnitude and \% THD have been shown in TABLE 3 .

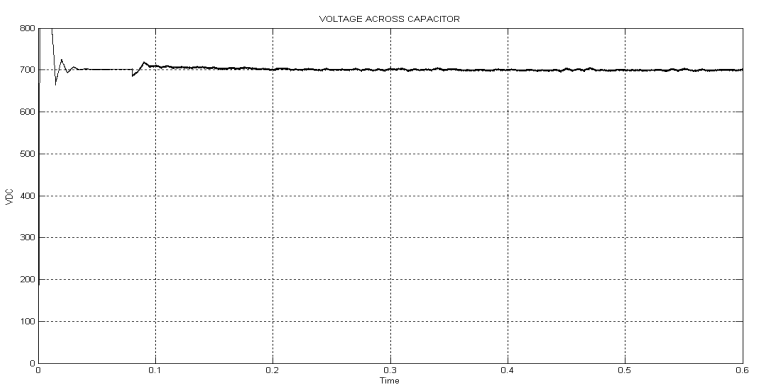

Fig 5. Simulated results of voltage across capacitor (or) load 
In fig.5 Shows that $V_{d c}$ constantly maintained at $700 \mathrm{~V}$ even though load is suddenly changes from $-7 \mathrm{KW}$ to $12.6 \mathrm{KW}$. The equivalent drive load variation is shown in fig. 6.

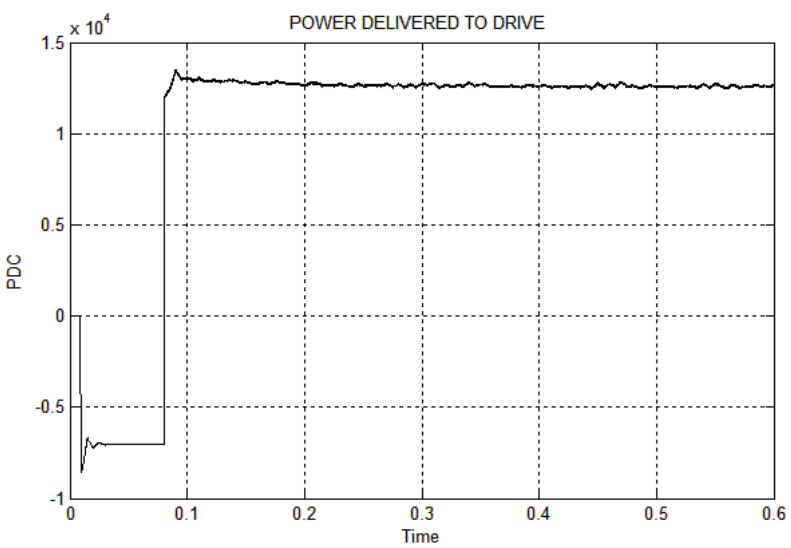

Fig 6. simulated results of power delivered by capacitor (or) load

Table-3

\begin{tabular}{|l|l|l|l|l|l|l|}
\hline \multirow{2}{*}{$\begin{array}{l}\text { Time } \\
(\mathrm{sec})\end{array}$} & \multicolumn{2}{l|}{ Ia } & \multicolumn{2}{l|}{ Ib } & \multicolumn{2}{l|}{ Ic } \\
\hline 0.04 & PEAK & \%THD & PEAK & \%THD & PEAK & \%THD \\
\hline 0.06 & 14.19 & 5.32 & 14.2 & 5.15 & 14.18 & 5.34 \\
\hline 0.08 & 26.83 & 3.46 & 26.49 & 10.25 & 27.02 & 10.6 \\
\hline 0.1 & 26.88 & 2.93 & 26.92 & 2.86 & 26.99 & 3.03 \\
\hline 0.12 & 26.83 & 2.88 & 26.88 & 3.07 & 26.83 & 2.93 \\
\hline 0.14 & 26.63 & 2.9 & 26.66 & 2.84 & 26.65 & 2.9 \\
\hline 0.16 & 26.71 & 3.03 & 26.67 & 3.02 & 26.61 & 2.97 \\
\hline 0.18 & 26.44 & 2.86 & 26.48 & 3.06 & 26.42 & 3.05 \\
\hline
\end{tabular}

Case II: Unbalanced Linear Load

Three phase unbalanced $R L$ load as shown in Table-IV

Table-4

\begin{tabular}{|l|l|l|l|}
\hline Parameters & $\begin{array}{l}\text { Numerical } \\
\text { Values }\end{array}$ & $\begin{array}{l}\text { Numerical } \\
\text { Values }\end{array}$ & $\begin{array}{l}\text { Numeric } \\
\text { al } \\
\text { Values }\end{array}$ \\
\hline $\begin{array}{l}\text { THREE PHASE } \\
\text { SUPPLY }\end{array}$ & $\begin{array}{l}325 \\
\text { Vph(peak) } \\
50 \mathrm{~Hz}\end{array}$ & $\begin{array}{l}325 \\
\text { Vph(peak) } \\
, 50 \mathrm{~Hz}\end{array}$ & $\begin{array}{l}325 \\
\text { Vph(pea } \\
\mathrm{k}) \quad 250 \\
\mathrm{~Hz}\end{array}$ \\
\hline $\begin{array}{l}\text { ACTIVE } \\
\text { POWER }\end{array}$ & $1000 \mathrm{~W}$ & $500 \mathrm{~W}$ & $400 \mathrm{~W}$ \\
\hline $\begin{array}{l}\text { INDUCTIVE } \\
\text { REACTIVE } \\
\text { POWER }\end{array}$ & $40 \mathrm{VAR}$ & $500 \mathrm{VAR}$ & $500 \mathrm{VAR}$ \\
\hline
\end{tabular}

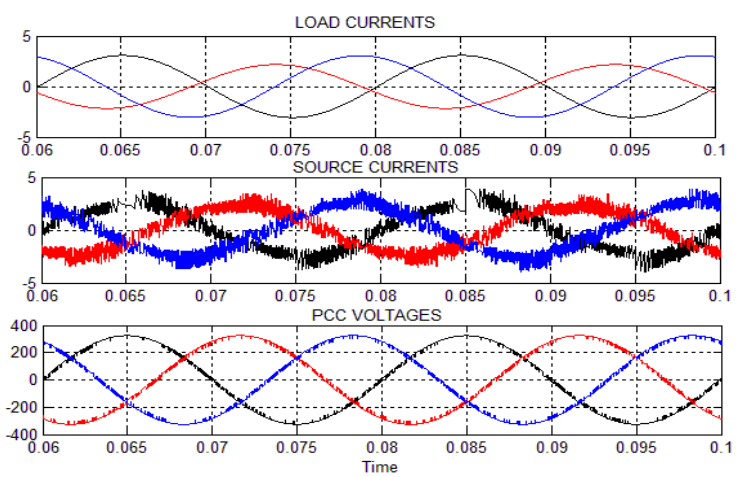

Fig 7. Simulated results of load currents, source currents and PCC voltages by placing a 3 phase unbalanced linear load

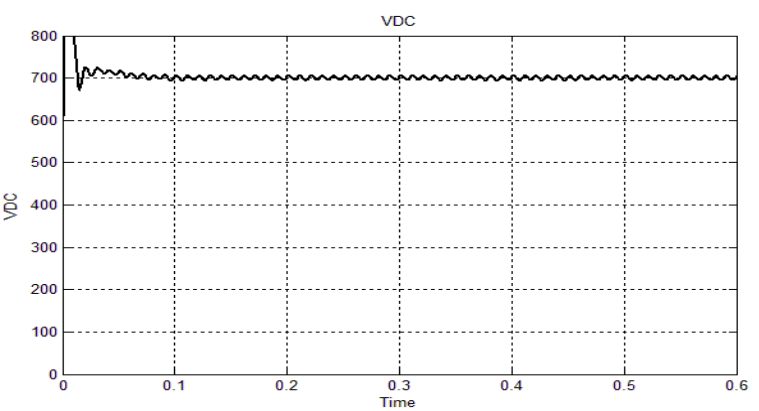

Fig 8.Simulated results of voltage across capacitor (or) load.

In Fig.7 shows simulated results of load currents, source currents and PCC voltages by placing a 3 phase unbalanced linear load and in Fig.8. $V_{d c}$ is constantly maintained as in case I.

\section{Case III: Non Linear Load}

$\mathrm{RL}$ load of $\mathrm{R}=70 \mathrm{ohm}, \mathrm{L}=2 \mathrm{mh}$ with 3 bridge diode rectifier

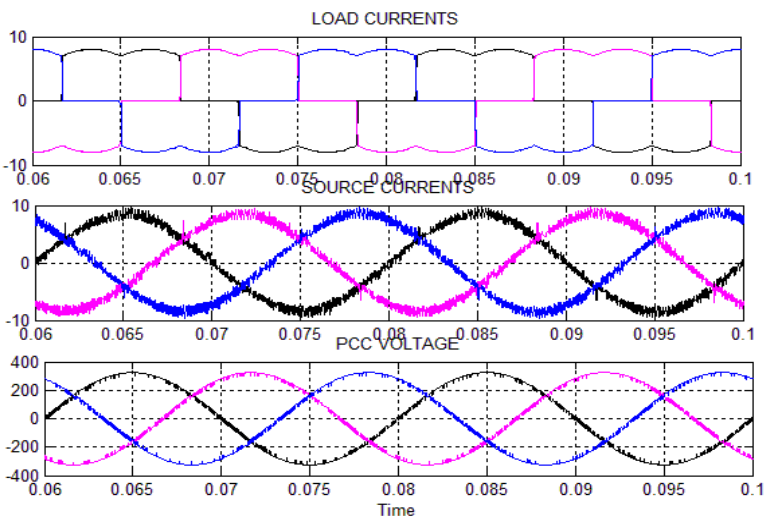

Fig 9. Simulated results of load currents, source currents and PCC voltages by placing a nonlinear load 
At $\mathrm{t}=0.04 \mathrm{~s}$ the source currents magnitude of $I_{a \max }=8.33 \mathrm{~A}$ and $\mathrm{THD}=9.3 \%$ and at $\mathrm{t}=0.18 \mathrm{~s}$ the source currents magnitude of $I_{a \max }=8.53 \mathrm{~A}$ and $\mathrm{THD}=8.51 \%$ nearly. Source current magnitude and \%THD have been shown in TABLE 5

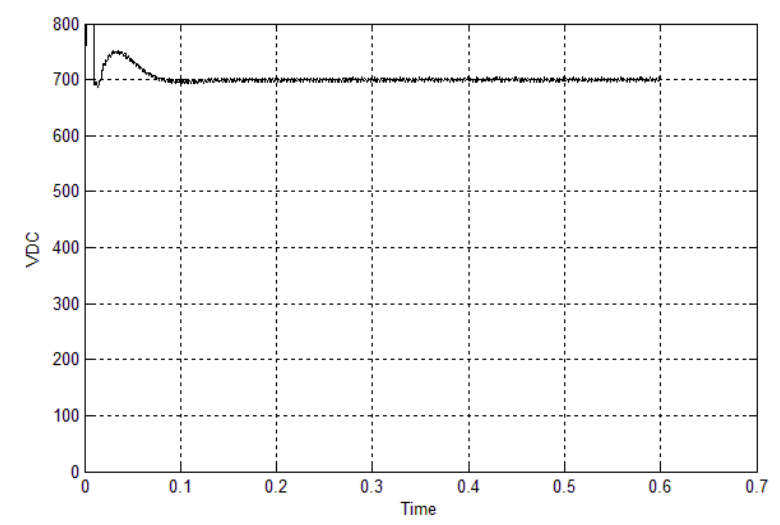

Fig 10.Simulated results of voltage across capacitor (or) load

In Fig 10. $V_{d c}$ is constantly maintained as in case I and II.

Table-5

\begin{tabular}{|c|c|c|c|c|c|c|}
\hline \multirow{2}{*}{$\begin{array}{l}\text { Time } \\
(\mathrm{sec})\end{array}$} & \multicolumn{2}{|l|}{$\mathrm{Ia}$} & \multicolumn{2}{|l|}{$\mathrm{Ib}$} & \multicolumn{2}{|l|}{ Ic } \\
\hline & PEAK & $\%$ THD & PEAK & $\% \mathrm{THD}$ & PEAK & $\%$ THD \\
\hline 0.04 & 8.33 & 9.3 & 8.288 & 9.21 & 8.324 & 8.95 \\
\hline 0.06 & 8.382 & 8.88 & 8.36 & 8.8 & 8.445 & 8.68 \\
\hline 0.08 & 8.492 & 8.37 & 8.442 & 8.49 & 8.524 & 8.36 \\
\hline 0.1 & 8.538 & 8.19 & 8.529 & 8.17 & 8.586 & 8.33 \\
\hline 0.12 & 8.517 & 8.38 & 8.523 & 8.31 & 8.535 & 8.51 \\
\hline 0.14 & 8.517 & 8.3 & 8.544 & 8.55 & 8.516 & 8.41 \\
\hline 0.16 & 8.558 & 8.54 & 8.513 & 8.29 & 8.54 & 8.41 \\
\hline 0.18 & 8.532 & 8.41 & 8.495 & 8.36 & 8.581 & 8.39 \\
\hline
\end{tabular}

\section{Case IV: Unbalanced Linear Load and Non Linear}

\section{Load}

In this case we are combining the case II and case III.
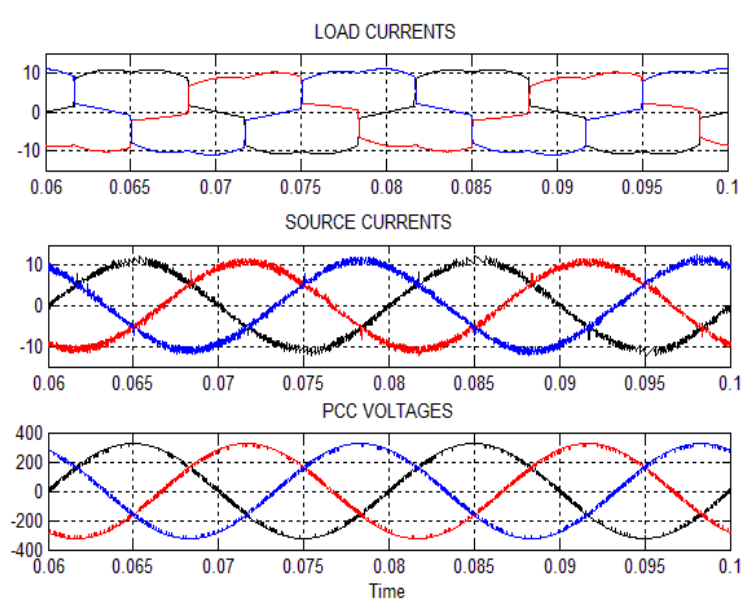

Fig 11.Simulated results of load currents, source currents and PCC voltages by placing a unbalanced linear and nonlinear load

At $\mathrm{t}=0.04 \mathrm{~s}$ the source currents magnitude of $I_{a \max }=10.81 \mathrm{~A}$ and $\mathrm{THD}=7.33 \%$ and at $\mathrm{t}=0.18 \mathrm{~s}$ the source currents magnitude of $I_{a \max }=11.15 \mathrm{~A}$ and THD $=6.46 \%$ nearly. Source current magnitude and \%THD have been shown in TABLE VI. There is no variation in the results due to no DC Side Equivalent Drive load.

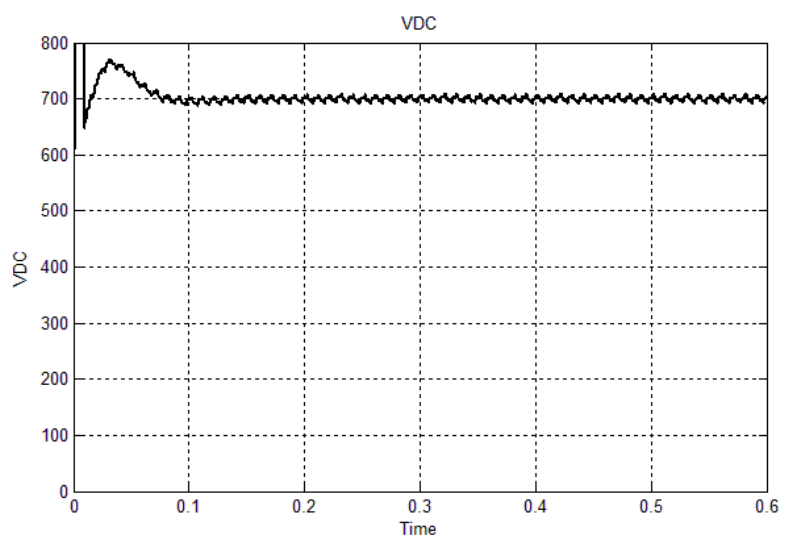

Fig 12.Simulated results of voltage across capacitor (or) load In Fig $9 V_{d c}$ is constantly maintained as in case I ,II and III .

Table-6

\begin{tabular}{|l|l|l|l|l|l|l|}
\hline \multirow{2}{*}{$\begin{array}{l}\text { Time } \\
(\mathrm{sec})\end{array}$} & \multicolumn{2}{|l|}{ Ia } & \multicolumn{2}{l|}{ Ib } & \multicolumn{2}{l|}{ Ic } \\
\hline 0.04 & PEAK & \%THD & PEAK & \%THD & PEAK & \%THD \\
\hline 0.06 & 10.81 & 7.33 & 10.69 & 7.32 & 10.79 & 6.84 \\
\hline 0.08 & 11.11 & 6.89 & 10.73 & 6.79 & 10.95 & 6.71 \\
\hline
\end{tabular}




\begin{tabular}{|l|l|l|l|l|l|l|}
0.1 & 11.13 & 6.47 & 10.87 & 6.56 & 11.13 & 6.47 \\
\hline 0.12 & 11.13 & 6.61 & 10.94 & 6.34 & 11.09 & 6.51 \\
\hline 0.14 & 11.13 & 6.79 & 10.88 & 6.67 & 11.14 & 6.55 \\
\hline 0.16 & 11.13 & 6.55 & 10.88 & 6.45 & 11.12 & 6.48 \\
\hline 0.18 & 11.15 & 6.46 & 10.88 & 6.64 & 11.14 & 6.69 \\
\hline
\end{tabular}

\section{Case V: Unbalanced Linear Load, Non Linear Load and DC Side Equivalent Drive load}
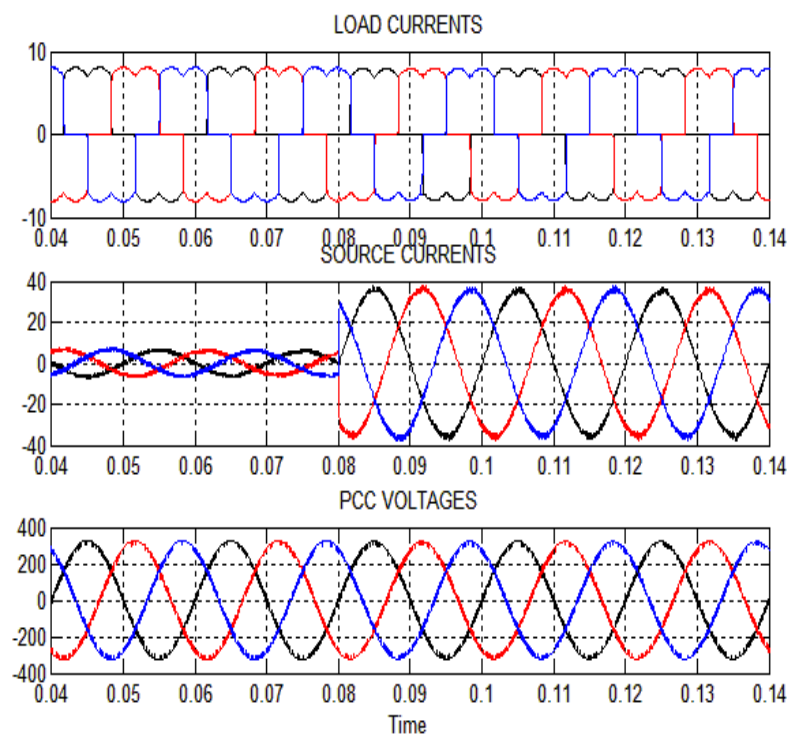

Fig 13. Simulated results of load currents, source currents and PCC voltages by placing a unbalanced linear, nonlinear load and DC Side Equivalent Drive load

In this case we are combining case I and case IV At the beginning of operation, at $\mathrm{t}=0$ there is no load hence the source current is zero, at $\mathrm{t}=0.01 \mathrm{~s}$ the load is applied to the DC side as 10 A of equivalent drive load which can treated as regenerative mode along with unbalanced linear and non linear load is applied and from $\mathrm{t}=0.08 \mathrm{~s}$ onwards load considered for motoring mode as 18 A load connected to the DC voltage. Even though the load changes abruptly the source currents are in sinusoidal with change of magnitude. During first interval no load is applied, second interval regenerative load $-10 \mathrm{~A}$ is applied and draws the source currents of peak value $I_{a \max }=6.472 \mathrm{~A}$ and THD in an around $11.22 \%$, third interval load is an motoring mode of $18 \mathrm{~A}$, draws power from the source current magnitude of $I_{a \max }=35.81 \mathrm{~A}$ and at thd of $2.54 \%$ nearly. Source current magnitude and \% THD have been shown in TABLE VII. There is variation in the current wave form due to DC Side Equivalent Drive load as the DC Side Equivalent.

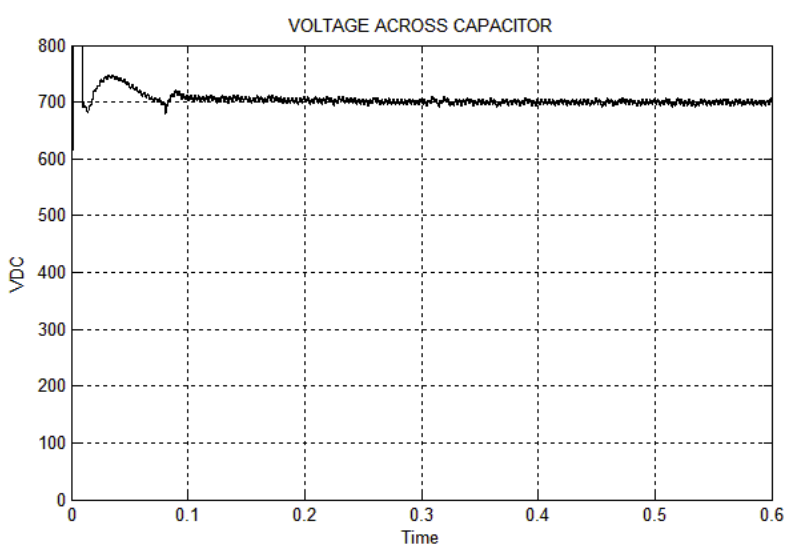

Fig 14.Simulated results of voltage across capacitor (or) load

In Fig 14. $V_{d c}$ is constantly maintained as in all cases. In this case also $V_{d c}$ is constantly maintained even though load changes suddenly due to the usage of PI controller at the Active Front End converter.

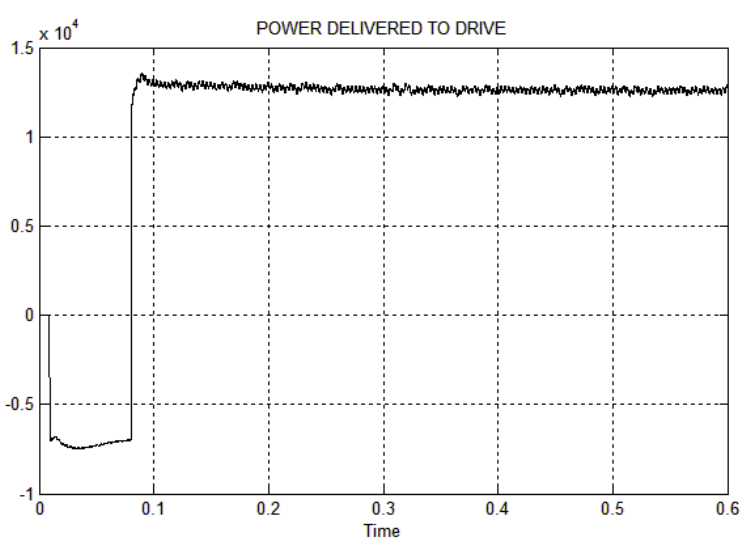

Fig 15.simulated results of power delivered by capacitor (or) load

Table-7

\begin{tabular}{|c|c|c|c|c|c|c|}
\hline \multirow{2}{*}{$\begin{array}{l}\text { Tim } \\
\text { e } \\
(\mathrm{sec})\end{array}$} & \multicolumn{2}{|l|}{ Ia } & \multicolumn{2}{|l|}{$\mathrm{Ib}$} & \multicolumn{2}{|l|}{ Ic } \\
\hline & $\begin{array}{l}\text { PEA } \\
\mathrm{K}\end{array}$ & $\begin{array}{l}\% \mathrm{TH} \\
\mathrm{D}\end{array}$ & $\begin{array}{l}\text { PEA } \\
\mathrm{K}\end{array}$ & $\begin{array}{l}\% \mathrm{TH} \\
\mathrm{D}\end{array}$ & $\begin{array}{l}\text { PEA } \\
\mathrm{K}\end{array}$ & $\begin{array}{l}\% \mathrm{TH} \\
\mathrm{D}\end{array}$ \\
\hline 0.04 & 6.472 & 11.22 & 6.454 & 11.36 & 6.507 & 11.18 \\
\hline 0.06 & 5.95 & 12.02 & 5.889 & 12.19 & 5.959 & 12.1 \\
\hline 0.08 & 35.81 & 2.54 & 35.38 & 8 & 35.59 & 7.95 \\
\hline 0.1 & 35.39 & 2.53 & 35.38 & 2.61 & 35.43 & 2.51 \\
\hline 0.12 & 35.18 & 2.64 & 35.2 & 2.63 & 35.39 & 2.63 \\
\hline 0.14 & 35.21 & 2.56 & 35.27 & 2.49 & 35.37 & 2.56 \\
\hline 0.16 & 35.12 & 2.57 & 35.24 & 2.47 & 35.26 & 2.62 \\
\hline 0.18 & 35.04 & 2.5 & 34.98 & 2.42 & 35.14 & 2.55 \\
\hline
\end{tabular}




\section{CONCLUSIONS}

The proposed combined active front end converter (AFE) and shunt active filter (SAF) is able to compensate reactive power, harmonic power and unbalanced power which are introduced by non linear and unbalanced linear load, at the same time combined AFE and SAF is able to convert the three phase AC to DC power without polluting the source currents, in this paper P-Q theory used as the control algorithm for the combined AFE and SAF, hence this theory gives appreciable \%THD [17] for source currents for all load as consider in 5 cases. The whole simulation has been carried out on the mat lab/ simulink environmental plot form which gives recommendable results.

\section{REFERENCES}

[1] Luu Hong Viet, "Control Of Front-End Converter With Shunt Active Filter Using P-Q Theory And Deadbead Technique," IEEE Compatibility in Power Electronics, PP.114-119, IEEE , 2005

[2] H. Akagi, Y. Kanazawa, and A. Nabae, "Instantaneous reactive power compensator comprising switching devices without energy storage components," IEEE Trans. Ind. Appl. , vol. IA-20, no. 3, pp. 625-630, Mar. 1984

[3] Eduardo P. Wiechmann, Roland P. Burgos, Josc R. Rodriguez, "Reduced Switching Frequency Active Front End Converter For Medium Voltage Current-Source Drives Using Space Vector Modulation," IEEE International Symposium on Industrial Electronics, PP.288-293, ISIE 2000

[4] M. Fioretto, G. Raimondo, L. Rubino, N. Serbia, P. Marino "Evaluation Of Current Harmonic Distortion In Wind Farm Application Based on Synchronous Active Front End Converters," PP.1-6, IEEE , 2011

[5] K.P. Louganski, Jih-Sheng Lai, "A 20-Kw, 10-Khz, Single-Phase Multilevel Active-Front-End Converter With Reactive Power Control,",IEEE Industry Applications Conference, PP.576-582, IEEE, 2006

[6] Yongsug Suh, Yuran Go, "A Comparative Study On Control Algorithm For Active Front-End Rectifier Of Large Motor Drives Under Unbalance Input," IEEE Trans. On Ind. Applications, Vol. 47,Pp. 1419 1431 ,IEEE , 2011

[7] Chung-Chuan Hou, Po-Tai Cheng, "Experimental Verification of The Active Front-End Converters Dynamic Model And Control Designs," IEEE Trans. On Power Electronics, vol. 26, no. 4, PP.1112 - 1118, 2011

[8] Francisco Huerta, Sebastian Stynski, Santiago Cóbreces, Mariusz Malinowski, Francisco J. Rodríguez, "Novel Control Of Three-Phase Active Front-End Converter With Compensation Of Unknown Grid-Side Inductance," IEEE Trans. On Ind. Elects., Vol. 58, No. 8, Pp. 3275,2010

[9] Chuang Liu, Pengwei Sun, Jih-Sheng Lai, Yanchao Ji, Mingyan Wang, Chien-Liang Chen, Guowei Cai, "Cascade Dual-Boost/Buck Active-Front-End Converter
For Intelligent Universal Transformer," IEEE Trans. On Ind. Elects., Vol. 59 , PP. 4671 - 4680 ,IEEE 2011

[10] Frenco Hernandez C, Luis Moran T, Jose Espinoza C, Juan Dixon R, "A Generalized Control Scheme For Active Front-End Multilevel Converters," ,IEEE Industrial Electronics Society Vol.2,PP. 915 - 920, 2001

[11] Tzung-Lin Lee Zong-Jie Chen Shang-Hung Hu, "Design Of A Power Flow Control Method For Hybrid Active Front-End Converters," IEEE International Conference on Power Electronics and Drive Systems,. PP.133 138, 2009

[12] Yongsug Suh, Yuran Go, Dohwan Rho, "A Comparative Study On Control Algorithm For Active Front-End Rectifier Of Large Motor Drives Under Unbalanced Input,",IEEE Transactions On Industry Applications, vol. 47, no. 32011 pp. 1419 to 1431, IEEE 2011

[13] Tzung-Lin Lee, Yen-Ching Wang "An Improved Control Strategy For Hybrid Active Front-End Converters In Grid-Connected Applications," International Power Electronics Conference (IPEC),PP. 3220 - 3224, IEEE , 2010

[14] M.L. Aime, S. Facelli, F. Profumo, "Unified Control Design Of Active Front-End Converters And Active Power Filters," IEEE Industry Applications Conference, Vol. 1 PP. 186 - 193 ,IEEE ,2001

[15] Milijana Odavi, Eljko Jakopovi, Fetah Koloni, "Sinusoidal Active Front End Under The Condition Of Supply Distortion," Automatika (0005-1144) 3-4 (2005); pp. 135-141.

[16] S.Garlapati, Rajesh Gupta,"Shunt active power filter as front end converter for DC loads," IEEE 5th India International Conference on Power Electronics (IICPE), dec,2012, pp. 1-6.

[17] IEEE Standard 519-1992, Recommended Practices and Requirements for Harmonic Control in Electrical Power Systems, The Institute of Electrical and Electronics Engineers, 1993 